\title{
Automatic Computing Methods for Special Functions. Part III. The Sine, Cosine, Exponential Integrals, and Related Functions
}

\author{
Irene A. Stegun and Ruth Zucker \\ Institute for Basic Standards, National Bureau of Standards, Washington, D.C. 20234
}

(April 29, 1976)

\begin{abstract}
Accurate, efficient, automatic methods for computing the sine, cosine, exponential integrals and hyperbolic sine and cosine integrals are detailed and implemented in an American National Standard FORTRAN program. The functions are also tabulated to 35 significant figures for arguments 0 , $10^{J}\left(10^{J}\right) 10^{J+1}$ with $J=-2(1) 2$.
\end{abstract}

Key words: Continued fraction; cosine integral; exponential integral; FORTRAN program; hyperbolic sine and cosine integrals; key values; recurrence relations.

\section{Introduction}

Since the sine, cosine, exponential integrals and hyperbolic sine, and cosine integrals are frequently encountered together in physical problems and their expansions have terms in common, we have incorporated these functions into Part III. (For Parts I and II, see. ${ }^{1}$ ).

While accuracy over the entire domain of definition remains our main concern, we have tended toward methods that also ensure efficiency, portability, and ease of programming and modification. The number of terms in series, the number of convergents in an iterative process, the starting arguments for different methods, are all determined by the program as a function of word length, arguments, accuracy desired, etc. More realistic results are returned when error conditions are encountered. The proper analytic behavior of the function will always be retained to further ensure correct limiting values, in particular of related functions and for purposes of differentiation and integration.

In Parts I and II in addition to the implementing ANS FORTRAN program, we had included a driver (test) program and its results. Since either of these driver programs can be readily modified to compute other functions, we have omitted the driver program and in place of its results have included a table of correct results to 35 significant figures covering essentially the functional range of present computers.

\section{Mathematical Properties}

Relevant formulas are collected here for completeness and ease of reference. In keeping with the convention of the Handbook [1], ${ }^{2} x$ here is a real variable.

${ }^{1}$ Automatic Computing Methods for Special Functions. Part I. Error, Probability, and Related Functions, J. Res. Nat. Bur. Stand. (U.S.), 74B. (Math. Sci), No. 3, 211-224 (July-Sept. 1970). Automatic Computing Methods for Special Functions. Part II. The Exponential Integral $E_{n}(x)$. J. Res. Nat. Bur. Stand. (U.S.), 78B, (Math. Sci), No. 4, 199-216 (Oct.-Dec. 1974).

${ }^{2}$ Figures in brackets indicate the literature references on page 


\section{A. Definitions}

$$
\begin{aligned}
& \operatorname{Si}(x)=\int_{0}^{x} \frac{\sin t}{t} d t \\
& C i(x)=\gamma+\ln x+\int_{0}^{x} \frac{\cos t-1}{t} d t \\
& \operatorname{Ei}(x)=-t_{-x}^{x} \frac{e^{-t}}{t} d t=f_{-\infty}^{x} \frac{e^{t}}{t} d t \quad(x>0)
\end{aligned}
$$

(For $\int_{x}^{\infty} \frac{e^{-t}}{t} d t=E_{1}(x)$, often denoted by $-E i(-x)$, see Part II.)

$$
\begin{aligned}
\operatorname{Shi}(x) & =\int_{0}^{x} \frac{\sinh t}{t} d t \quad=\frac{E i(x)+E_{1}(x)}{2} \\
\operatorname{Chi}(x) & =\gamma+\ln x+\int_{0}^{x} \frac{\cosh t-1}{t} d t=\frac{E i(x)-E_{1}(x)}{2} \\
\gamma & \text { (Euler's constant) }=0.5772156649 \ldots
\end{aligned}
$$

\section{B. Series Expansions}

$$
\begin{aligned}
\operatorname{Si}(x) & =\sum_{k=0}^{\infty} \frac{(-1)^{k} x^{2 k+1}}{(2 k+1)(2 k+1) !} \\
\operatorname{Ci}(x) & =\gamma+\ln x+\sum_{k=1}^{\infty} \frac{(-1)^{k} x^{2 k}}{(2 k)(2 k) !} \\
\operatorname{Ei}(x) & =\gamma+\ln x+\sum_{k=1}^{\infty} \frac{x^{k}}{(k)(k) !} \quad(x>0) \\
\operatorname{Shi}(x) & =\sum_{k=0}^{\infty} \frac{x^{2 k+1}}{(2 k+1)(2 k+1) !} \\
\operatorname{Chi}(\mathbf{x}) & =\gamma+\ln x+\sum_{k=1}^{\infty} \frac{x^{2 k}}{(2 k)(2 k) !}
\end{aligned}
$$

C. Continued Fraction

$$
\begin{gathered}
-C i(x)+i[S i(x)-\pi / 2]=e^{-i x}\left[\frac{1}{i x+1+i x+1+i x+\ldots} \frac{1}{1+\ldots} \frac{1}{2} \frac{2}{(0<x)}\right. \\
=E_{1}(i x)
\end{gathered}
$$




\section{Asymptotic Expansions}

$$
\begin{aligned}
& S i(x)=\pi / 2-f(x) \cos x-g(x) \sin x \\
& C i(x)=f(x) \sin x-g(x) \cos x
\end{aligned}
$$

where $f(x) \sim \frac{1}{x} \sum_{k=0}^{\infty} \frac{(-1)^{k}(2 k) !}{x^{2 k}}$

and $g(x) \sim \frac{1}{x} \sum_{k=0}^{\infty} \frac{(-1)^{k}(2 k+1) !}{x^{2 k+1}}$

$$
\begin{gathered}
\operatorname{Ei}(x) \sim \frac{e^{x}}{x} \sum_{k=0}^{\infty} \frac{k !}{x^{k}} \quad(x>0) \\
\operatorname{Shi}(x)=\frac{1}{x}[p(x) \cosh x+q(x) \sinh x] \\
\operatorname{Chi}(x)=\frac{1}{x}[p(x) \sinh x+q(x) \cosh x]
\end{gathered}
$$

where $p(x) \sim \sum_{k=0}^{x} \frac{(2 k) !}{x^{2 k}}$

and $q(x) \sim \sum_{k=0}^{\infty} \frac{(2 k+1) !}{x^{2 k+1}}$

E. Special Values

$$
\begin{array}{lll}
\operatorname{Si}(0)=0 & \operatorname{Ci}(0)=-x & \operatorname{Ei}(0)=-x \\
\operatorname{Shi}(0)=0 & & \operatorname{Chi}(0)=-x
\end{array}
$$

F. Symmetry Relations

$$
(x>0)
$$

$$
\begin{aligned}
& \operatorname{Si}(-x)=-\operatorname{Si}(x) \quad C i(-x)=\operatorname{Ci}(\mathrm{x})-i \pi \\
& \operatorname{Sh} i(-x)=-\operatorname{Sh} i(x) \quad \operatorname{Chi}(-x)=\operatorname{Chi}(x)-i \pi
\end{aligned}
$$

G. Interrelations

$$
\begin{aligned}
& \operatorname{Si}(x)=\frac{1}{2 i}\left[E_{1}(i x)-E_{1}(-i x)\right]+\pi / 2 \\
& \operatorname{Ci}(x)=-\frac{1}{2}\left[E_{1}(i x)+E_{1}(-i x)\right] \\
& \operatorname{Ei}(x)=-\frac{1}{2}\left[E_{1}(-x+i 0)+E_{1}(-x-i 0)\right] \quad(x>0)
\end{aligned}
$$


H. Value at Infinity

$$
\lim _{x \rightarrow x} \operatorname{Si}(x)=\pi / 2
$$

I. Related Function

Logarithmic Integral

$$
l i(x)=E i(\ln (x)) \quad(x>1)
$$

\section{Method}

Evaluation of the integrals by means of quadrature formulas suited to the particular type of integrand tends to be inefficient and inaccurate. For $\operatorname{Si}(x)$ and $\operatorname{Ci}(x)$, the use of the asymptotic expansion is not valid for moderate values of $x$, while the use of the continued fraction is inefficient and also inaccurate for small values of $x$. An examination of the series expansion for the functions indicates several difficulties. Summation of the alternating series for $\operatorname{Si}(x)$ and $\operatorname{Ci}(x)$ will lead to greater round-off errors as $x$ increases. The partial sum at a particular value of $k$ may be zero. Additionally there may be cancellations in adding the logarithmic term and/or Euler's constant for $C i(x), E i(x)$ and $C h i(x)$. The more rapidly accumulating round-off errors, in particular when summations are limited to a single register, eliminate the prolonged use of the series expansion. Since the maximum of $\operatorname{Ci}(x)$ occurs at $\pi / 2$ and $\operatorname{Si}(x)=\pi / 2$ at $x \simeq 1.92$, testing indicates $x=$ 2 (PSLSC) as a reasonable starting point for the use of the continued fraction. The starting point for the valid use of the asymptotic expansion for $\operatorname{Si}(x)$ and $\operatorname{Ci}(x)$ does not coincide with the starting point for $\operatorname{Ei}(x)(S h i(x)$ and $\operatorname{Chi}(x))$. Testing also indicates that fewer terms are needed in the continued fraction than in the asymptotic expansion.

The following table gives an indication of the number of terms needed to obtain maximum machine accuracy for particular values of $x$ with the various methods of computation. Throughout

\begin{tabular}{|c|c|c|c|c|c|c|}
\hline \multirow{3}{*}{$\begin{array}{l}\text { Method } \\
x=2\end{array}$} & \multicolumn{6}{|c|}{ Number of Terms } \\
\hline & \multicolumn{3}{|c|}{$N B M=27$} & \multicolumn{3}{|c|}{$N B M=60$} \\
\hline & $\operatorname{Si}(x)$ & $C i(x)$ & $E i(x)$ & $S i(x)$ & $C i(x)$ & $E i(x)$ \\
\hline $\begin{array}{l}\text { Power Series } \\
\text { Continued Fraction } \\
\text { (Even Form) }\end{array}$ & $\begin{array}{r}7 \\
24\end{array}$ & $\begin{array}{r}7 \\
24\end{array}$ & 13 & $\begin{array}{r}12 \\
106\end{array}$ & $\begin{array}{r}12 \\
106\end{array}$ & 23 \\
\hline $\begin{array}{l}\text { Numerical Integration } \\
\text { (Trapezoidal or Simpson's Rule) }\end{array}$ & 64 & 128 & 64 & - & - & - \\
\hline $\begin{array}{l}\text { Power Series } \quad x=24 \\
\text { Asymptotic Expansion } \\
\text { Continued Fraction } \\
\text { Numerical Integration }\end{array}$ & $\begin{array}{r}\mathrm{a}-\overline{11} \\
5 \\
512\end{array}$ & $\begin{array}{r}7, \overline{11} \\
5 \\
512\end{array}$ & $\begin{array}{r}55 \\
13 \\
1024\end{array}$ & $\begin{array}{l}- \\
- \\
-\end{array}$ & $\begin{array}{l}- \\
- \\
-\end{array}$ & $\begin{array}{l}80 \\
- \\
-\end{array}$ \\
\hline $\begin{array}{l}\text { Power Series } \quad x=48 \\
\text { Asymptotic Expansion } \\
\text { Continued Fraction }\end{array}$ & $\begin{array}{r}\overline{4,5} \\
4\end{array}$ & $\overline{4,5}$ & $-{ }^{-}$ & $\begin{array}{r}16, \overline{2} 3 \\
9\end{array}$ & $\begin{array}{r}16,23 \\
9\end{array}$ & $\begin{array}{r}119 \\
31 \\
-\end{array}$ \\
\hline $\begin{array}{l}\qquad x=88 \\
\text { Asymptotic Expansion } \\
\text { Continued Fraction }\end{array}$ & $\begin{array}{r}3,4 \\
5\end{array}$ & $\begin{array}{r}3,4 \\
5\end{array}$ & 6 & $\begin{array}{r}9,10 \\
8\end{array}$ & $\begin{array}{r}9,10 \\
8\end{array}$ & 17 \\
\hline
\end{tabular}
the paper, NBM is the maximum number of binary digits in the mantissa of a floating point number, and TOLER $=2^{-\mathrm{NBM}}$.

a We indicate the number of odd and even terms of the respective series.

The most accurate, efficient, automatic methods for $\operatorname{Si}(x)$ and $C i(x)$ then are the power series and the continued fraction; for $\operatorname{Ei}(x), \operatorname{Shi}(x)$ and $\operatorname{Chi}(x)$ the power series and the asymptotic 
expansion. The lower limit (AELL) for the use of the asymptotic expansion may be shown to approximate $|\ln T O L E R|=N B M(\ln 2)$, where TOLER is the requested upper limit for the relative error. With this choice of the lower limit, one can also show that $\operatorname{Shi}(x) \simeq \operatorname{Chi}(x) \simeq \frac{1}{2} \operatorname{Ei}(x)$. It is necessary then to consider only the asymptotic expansion for $\operatorname{Ei}(x)$.

The series computations have been so arranged that the maximum number of functions may be obtained in a minimum of time. The even and odd terms of the series are summed independently both with and without the factor $(-1)^{k}$. Since $\operatorname{Si}(x)-\pi / 2$ and $\operatorname{Ci}(x)$ are the imaginary and real parts respectively of the continued fraction expansion for $E_{1}(i x)$, there would be a saving in computing time with options on the functions to be computed. Invalid results are initially supplied for all functions. With the parameter $I C=1, S i(x)$ and $C i(x)$ only are computed; with $I C=2, E i(x)$ and $e^{-x} \operatorname{Ei}(x)$ only; with $I C=3, E i(x), e^{-x} \operatorname{Ei}(x)$, Shi $(x)$ and $\operatorname{Chi}(x)$ only and with $I C=4$, all functions are computed.

The implementing program checks the input parameters. If $I C$ is outside the range $1-4$. the working indicator IND is automatically set equal to 4 . Since $E i(x)$ is defined for positive $x$ only, if $I C$ $=2$ and $x<0$, there is an error return and the indicator IERR is set equal to 1 . If $x<0, I C=3$, Shi(x) and Chi(x) are computed; for $I C=4, \operatorname{Si}(x)$ and $\operatorname{Ci}(x)$ are also computed, invalid results are returned for $\operatorname{Ei}(x)$ and $e^{-x} \operatorname{Ei}(x)$ and the indicator IERR is set equal to 1 . For $x>0$, the indicator IERR is set equal to zero and valid results are returned only for the functions requested by the parameter $I C$ (or IND).

The computations are performed for positive $x(=T)$ only. Before the return, use is then made of the symmetry relations. Various cases are treated independently. Among these are $x=0$ and $x$ equal to or greater than the supplied upper limit (ULSC) for the sine and cosine routine. The appropriate values of the functions are supplied. To avoid unnecessary computations of the exponential function and possible overflows and underflows in the final results, if $T$ is equal to or less than the upper limit for the relative error, the exponential of half the argument is set equal to 1 . If $T$ is equal to or greater than the computed limiting argument (XMAXHF) for Shi(x) and Chi(x), the maximum machine value (RINF) is supplied for the exponential of half the argument as well as for Shi $(x)$ and $\operatorname{Chi}(x)$. The computed limiting argument (XMAXEI) for $E i(x)$ can be shown to be approximately $\ln \mathrm{RINF}+\ln [\ln \mathrm{RINF}+\ln (\ln \mathrm{RINF})]-1 / \ln \mathrm{RINF}$. The value of XMAXHF is approximately XMAXEI $+\ln 2$. The computation of $e^{x / 2}$ provides a slight improvement in accuracy and an extension of the range of $x$. Throughout the program, overflows are avoided as well as underflows affecting accuracy. Other underflows are assumed to be set equal to zero.

For $|x| \leq$ PSLSC $(=2)$, all functions are computed by means of the power series. For $|x|>$ PSLSC, $S i(x)$ and $C i(x)$ are computed by means of the continued fraction. Only if $I C=4$ is the working indicator IND set equal to 3 . The functions $\operatorname{Ei}(x), e^{-x} \operatorname{Ei}(x)$, Shi(x) and $\operatorname{Chi}(x)$ are then computed by means of the power series or the asymptotic expansion depending on whether $|x| \leq$ AELL or $>$ AELL respectively. With $\mathrm{NBM}=27$, AELL $\approx 18.7$ and with $\mathrm{NBM}=60$, AELL $\approx$ 41.6. To avoid underflow, $|x|$ is tested against a lower limit argument PSLL $(=2 \sqrt{ }$ AMIN $)$. To simplify computation, AMIN, a minimum machine value is computed as the reciprocal of the maximum machine value (RINF). If $|x| \leq$ PSLL, only the first term of the series of odd terms is used.

The following series definitions are in use

$$
\begin{array}{rlrl}
S i(x) & =\mathrm{SI}=\mathrm{SUMS}=\sum \mathrm{SGN}(R K)^{*} T M(R K) & I P=-1(R K=1,3, \ldots) \\
C i(x) & =\mathrm{CI}=\mathrm{SUMC}+X \mathrm{LOG}+\mathrm{EULER} & & \\
& \text { where SUMC }=\sum \mathrm{SGN}(R K)^{*} T M(R K) & I P=1(R K=2,4, \ldots) \\
\operatorname{Ei}(x) & =\mathrm{EI}=\mathrm{SUMET}+\mathrm{SUMOT}+X \mathrm{LOG}+\mathrm{EULER} & & \\
\text { Shi }(x) & =\mathrm{SHI}=\mathrm{SUMOT}=\sum T M(R K) & I P=-1(R K=1,3, \ldots) \\
C h i(x) & =\mathrm{CHI}=\mathrm{SUMET}\left[=\sum T M(R K)\right]+X \mathrm{LOG}+\mathrm{EULER} & I P=1(R K=2,4, \ldots)
\end{array}
$$

with $\mathrm{SGN}(1)=1, \mathrm{SGN}(R K+1)=-\mathrm{SGN}(R K)$ for $R K=1,3, \ldots$, and $\mathrm{SGN}(R K+1)=\mathrm{SGN}(R K)$ for $R K=2,4, \ldots$ The term $T M(R K)=\left[T^{k} / k !\right] / k=\operatorname{PTM}(R K) / R K$ where $\operatorname{PTM}(1)=T$ and $\operatorname{PTM}(R K+1)=\operatorname{PTM}(R K)[T /(\mathrm{RK}+1)], R K \geq 1$. 
The series of even and odd terms are always computed together. If the relative error RE computed as $T M /|\mathrm{SUM}|$ is less than the prescribed tolerance both series are considered to have converged. If IND $=1$ or 4 , SUM is replaced by SUMS or SUMC; otherwise by SUMET or SUMOT. To avoid underflow, in generating the terms for $|x| \leq 2$, if $\mathrm{PTM} \leq \operatorname{AMIN}(R K)^{2} / T$, the series are likewise considered to have converged. If the sum of terms is zero, the relative RE is automatically set equal to the maximum machine value. This condition is not encountered if the power series for $\operatorname{Si}(x)$ and $C i(x)$ is restricted to the region $|x| \leq 2$. It has been retained to permit the program's use for experimental purposes.

To enable the continued fraction computations to be performed in double precision, since complex quantities are involved, the real notation only is used. Testing has also confirmed the improved accuracy and efficiency of this course. The continued fraction for $\operatorname{Si}(x)$ and $\operatorname{Ci}(x)$ in its "even" form

$$
\begin{aligned}
E_{1}(i x)=-C i(x)+i[S i(x)-\pi / 2]= & e^{-i x}\left[\frac{1}{1+i x}-\frac{1}{3+i x}-\frac{4}{5+i x}-\ldots\right] \\
& e^{-i x}[F]
\end{aligned}
$$

is evaluated in the forward direction. The first convergent $F_{1} / G_{1}=A_{1} / B_{1}$ where $A_{1}=1, A_{\mathrm{M}}=-(M$ $-1)^{2}, B_{M}=2 M-1+i x$. If we define

$$
F_{-1}=1, F_{0}=0, G_{-1}=0 \text { and } G_{0}=1
$$

then successive convergents $F_{M} / G_{M}$ for $M=1,2, \ldots$ may be obtained by the following recurrence relation

$$
\begin{aligned}
& F_{M}=B_{M} F_{M-1}+A_{M} F_{M-2} \\
& G_{M}=B_{M} G_{M-1}+A_{M} G_{M-2}
\end{aligned}
$$

The continued fraction is considered to have converged either if in effect the relative error is equal to or less than the prescribed tolerance or the relative error increases.

Since the successive convergents are complex, $(\mathrm{RE})^{2}$ is compared with (TOLER) ${ }^{2}$ where $(\mathrm{RE})^{2}$ $=\left[\bmod \left(1-\frac{F_{M-1} / G_{M-1}}{F_{M} / G_{M}}\right)\right]^{2}$. Throughout the computation, to avoid overflow, there is scaling by the absolute maximum (=TMAX) of the real and imaginary parts of the numerator and denominator of the successive convergents. In addition, there is scaling by $\mid$ TMAX $\mid$ if the product of the real part of $\left(B_{M}-A_{M}\right)$ and $\mid$ TMAX $\mid$ is equal to or greater than $1 / 4$ the maximum machine value.

The successive terms of the asymptotic expansion are likewise obtained by recurrence with $T_{0}$ $=1$ and $T_{K}=[K / T] T_{K-1}$ for $K \geq 1$. Since the sum of terms for $\operatorname{Ei}(x)$ is always greater than one, the term itself is a good approximation to the relative error. The summation is terminated when a term is less than the prescribed tolerance or the term is equal to or greater than the preceding term. In the latter case, the preceding term is subtracted from the summation to minimize the error.

\section{Range}

The range for $\operatorname{Si}(x)$ and $\operatorname{Ci}(x)$ (as well as the accuracy) is limited to the range (and accuracy) of the sine and cosine routine $(|x|<\mathrm{ULSC})$. For the UNIVAC 1108, namely, $x<2^{21}$ in single precision and $x<2^{56}$ in double precision. For the function $E i(x)$, the range of $x$ is essentially the range of the exponential routine. The function $\operatorname{Ei}(x)$ is set equal to the machine maximum (RINF) for $x$ beyond XMAXEI, approximately 92.5 in single precision and 715.6 in double precision. For the function $e^{-x} \operatorname{Ei}(x)$ beyond $x$ = ULSC only the first two terms of the asymptotic expansion are used. The functions $\operatorname{Shi}(x)$ and $\operatorname{Chi}(x)$ are set equal to the maximum machine value for $x$ beyond XMAXHF, approximately 93.2 in single precision and 716.3 in double precision. 


\section{Accuracy and Precision}

Using the UNIVAC 1108 to compute the functions, the maximum relative error, except for regions in the immediate neighborhood of zeros, is $4.5(-7)$ for single precision compuțations and 7.5 $(-17)$ for double precision computations. Various auxiliary functions are available to greater accuracy at intermediate points in the subroutine. For example, since $S i(x) \rightarrow \pi / 2, S i(x)-\pi / 2$ should be taken as the imaginary part of the continued fraction. The functions $C i(x), \operatorname{Ei}(x)$ and $\operatorname{Chi}(x)-\gamma-\ln$ $x$ are available from the sum of the appropriate series.

The precision may be set lower than the maximum by varying the value of NBM or deleting NBM and setting a precomputed value of TOLER. The above relative errors give an indication of the allowance for round-off errors.

\section{Timing-UNIVAC 1108 Time/Sharing Executive System}

(The time estimates given below are highly dependent on the operating system environment and consequently should not be relied on for critical timing measurements.)

\begin{tabular}{|c|c|c|c|c|}
\hline \multicolumn{2}{|l|}{$\begin{array}{l}\text { Single Precision } \\
N B M=27\end{array}$} & \multicolumn{3}{|c|}{$\begin{array}{c}\text { Double Precision } \\
\qquad N B=60\end{array}$} \\
\hline \multicolumn{5}{|c|}{ For $S i(x)$ and $C i(x)$} \\
\hline Region & $\begin{array}{c}\text { Time } \\
\text { (seconds) }\end{array}$ & Region & $\begin{array}{c}\text { Time } \\
\text { (seconds) }\end{array}$ & Method \\
\hline $\begin{array}{ll}0(0.01) 2 & (201 \text { values }) \\
2(.5) 100 & \text { (197 values) } \\
\text { Maximum Time/Evaluation } & (x=2)\end{array}$ & $\begin{array}{l}0.40 \\
.56 \\
.0023 \\
.0093\end{array}$ & $\begin{array}{lc}0(.01) 2 & (201 \text { values }) \\
2(.5) 100 & (197 \text { values }) \\
& (x=2)\end{array}$ & $\begin{array}{l}0.98 \\
2.06 \\
0.0059 \\
.070\end{array}$ & $\begin{array}{l}\text { Power Series } \\
\text { Continued Fraction } \\
\text { Power Series } \\
\text { Continued Fraction }\end{array}$ \\
\hline \multicolumn{5}{|c|}{ For $E i(x)$} \\
\hline $\begin{array}{l}0(.1) 18 \quad(181 \text { values }) \\
18(.1) 41 \quad(231 \text { values }) \\
41(.25) 100 \quad(237 \text { values }) \\
\text { Maximum Time/Evaluation } \\
\qquad(x=18)\end{array}$ & $\begin{array}{l}0.54 \\
.28 \\
.25 \\
.0044 \\
.0015\end{array}$ & 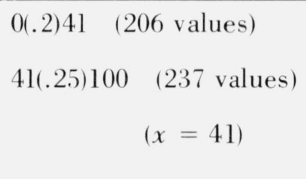 & $\begin{array}{l}2.05 \\
0.70 \\
.016 \\
.0040\end{array}$ & $\begin{array}{l}\text { Power Series } \\
\text { Asymptotic Expansion } \\
\text { Asymptotic Expansion } \\
\text { Power Series } \\
\text { Asymptotic Expansion }\end{array}$ \\
\hline
\end{tabular}

\section{Testing}

The double precision results obtained were compared against available published values. Check values were obtained, where appropriate, by overlapping the power series with either the asymptotic expansion or the continued fraction. Various forms of the continued fraction were also employed as well as numerical integration. Two multi-precision packages ${ }^{3}$ were also utilized with varied precision. The single and double precision results agreed with the multi-precision results within the reported accuracy.

\section{Many-Place Tables}

In the appendix, we have included three tables; one for $\operatorname{Si}(x)$ and $\operatorname{Ci}(x)$, one for $\operatorname{Ei}(x)$ and $e^{-x} \operatorname{Ei}(x)$ and one for $\operatorname{Shi}(x)$ and $\operatorname{Chi}(x)$. The functions are tabulated to 35 significant figures for $x=$ $0,10^{J}\left(10^{J}\right) 10^{J+1}$ with $\mathrm{J}=-2(1) 2$.

${ }^{3}$ (Private Communication) Peavy, Bradley A, A Multi-Precision Arithmetic Package for Use with the UNIVAC 1108

Wyatt, W. T. Jr., Lozier, D. W. and Orser, D. J., A Portable Extended-Precision Arithmetic Package and Library with FORTRAN Precompiler, ACM TOMS, Sept. 1975 


\section{Special Values}

Zeros

$$
\begin{aligned}
\operatorname{Si}\left(x_{s}\right) & =\pi / 2 \\
x_{0} & =1.926447660 \\
x_{1} & =4.893835953 \\
x_{2} & =7.972682624 \\
\operatorname{Ci}\left(x_{\mathrm{s}}\right) & =0 \\
x_{0} & =0.616505486 \\
x_{1} & =3.384180423 \\
x_{2} & =6.427047744 \\
\operatorname{Ei}(x) & =0 \\
x & =0.37250741078136663446199186658011913 \\
\operatorname{Chi}(x) & =0 \\
x & =0.52382 \quad 2571389864
\end{aligned}
$$

Maxima

$\operatorname{Si}(\pi)=1.851937051982466$

$C i(\pi / 2)=0.472000651439569$

Minima

$\operatorname{Si}(2 \pi)=1.418151576132628$

$C i(3 \pi / 2)=-0.198407560692358$

Related Constants

$$
\begin{aligned}
& \sum_{N=0}^{\infty} \frac{(-1)^{N}}{(2 N+1)(2 N+1) !}=S i(1) \quad=\quad 0.94608307036718301494135331382317965 \\
& \sum_{N=1}^{\infty} \frac{(-1)^{N}}{(2 N)(2 N) !} \quad=C i(1)-\gamma=-0.23981174200056472594386588619325166 \\
& \sum_{N=1}^{\infty} \frac{1}{(N)(N) !} \quad=E i(1)-\gamma=1.31790215145440389486000884424923183 \\
& \sum_{N=0}^{\infty} \frac{1}{(2 N+1)(2 N+1) !}=\operatorname{Shi}(1)=1.05725087537572851457184235489587795
\end{aligned}
$$

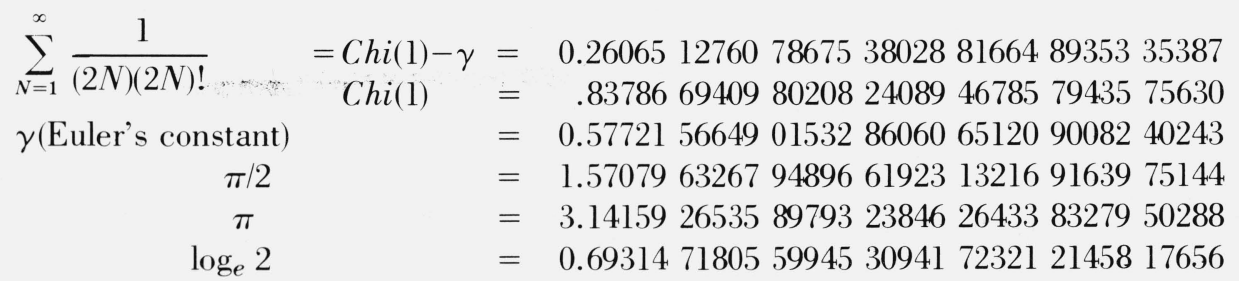




$$
\begin{aligned}
2^{-24} & =0.59604644775390625(-7) \\
2^{-27} & =.7450580596923828125(-8) \\
2^{-36} & =.14551915228366851806640625(-10) \\
2^{-48} & =3552713678800500929355621337890625(-14) \\
2^{-56} & =.1387778780781445675529539585113525390625(-16) \\
2^{-60} & =.867361737988403547205962240695953369140625(-18) \\
2^{-108} & =.308148791101957736488956470813588370966096263 \\
\log _{e}\left(2^{-24}\right) & =-16.63553233343868742601357091499623763 \\
\log _{e}\left(2^{-27}\right) & =-18.71497387511852335426526727937076733 \\
\log _{e}\left(2^{-36}\right) & =-24.95329850015803113902035637249435645 \\
\log _{e}\left(2^{-48}\right) & =-33.27106466687737485202714182999247526 \\
\log _{e}\left(2^{-56}\right) & =-38.81624211135693732736499880165788781 \\
\log _{e}\left(2^{-60}\right) & =-41.58883083359671856503392728749059408 \\
\log _{e}\left(2^{-108}\right) & =-74.85989550047409341706106911748306935
\end{aligned}
$$

Maximum and Minimum Machine Values and Their Natural Logarithms $\mathrm{NBC}=$ Number of binary digits in the (biased) characteristic of a floating point number

$$
\begin{aligned}
& 2^{-\left(2^{N B C-1}+1\right)} \leq x<2^{2^{N B C-1}-1} \\
& \mathrm{NBC}=8 \\
& 2^{127}=0.17014118346046923173168730371588410(39) \\
& 2^{-129}=.14693679385278593849609206715278070(-38) \\
& \log _{e}\left(2^{127}\right)=88.02969193111305429598847942518842414 \\
& \log _{e}\left(2^{-129}\right)=-89.41598629223294491482294366810477728 \\
& \mathrm{NBC}=11 \\
& 2^{1023}=0.89884656743115795386465259539451236(308) \\
& 2^{-1025}=.27813423231340017288627908966655050(-308) \\
& \log _{e}\left(2^{1023}\right)=709.08956571282405153382846025171462914 \\
& \log _{e}\left(2^{-1025}\right)=-710.47586007394394215266292449463098227
\end{aligned}
$$

\section{References}

[ 1] Abramowitz, M. and Stegun, I. A., Handbook of Mathematical Functions, Nat. Bur. Stand. (U. S.), Appl. Math. Ser. 55, (1964).

[ 2] Blanch, G., Numerical evaluation of continued fractions, SIAM Review 6, 4, 383-421(1964).

[ 3] British Association for the Advancement of Science, Mathematical Tables, Vol. 1, 3d ed. (Cambridge University Press, Cambridge, England, 1951).

[ 4] Glaisher, J. W. L., Tables of the numerical values of the sine-integral, cosine-integral and exponential-integral, Phil. Trans. Roy. Soc. London 160, 367-388(1870).

[ 5] Harris, F. E., Tables of the exponential integral Ei(x), MTAC 11, 9-16(1957).

[ 6] Lee, Kin L., High-precision Chebyshev series approximation to the exponential integral, NASA TN D-5953, 1970.

[ 7] Miller, James and Hurst, R. P., Simplified calculation of the exponential integral, MTAC 12, 187-193(1958).

[ 8] Murnaghan, Francis D., and Wrench, John W. Jr., The Converging Factor for the Exponential Integral, Report 1535, David Taylor Model Basin, 1963.

[ 9] National Bureau of Standards, Table of sine and cosine integrals for arguments from 10 to 100, Appl. Math. Ser. 32, (1954).

[10] National Bureau of Standards, Tables of Sine, Cosine and Exponential integrals, Vol. I \& II, MT5 and MT6, (1940). 


\begin{tabular}{|c|c|c|}
\hline 1* & C & APPENDIX \\
\hline $\begin{array}{l}2 * \\
3 *\end{array}$ & $\begin{array}{l}c \\
c\end{array}$ & IMPLEMENTING PROGRAM \\
\hline 4* & C & LANGUAGE. AMERICAN NATIONAL STANDARD FORTRAN \\
\hline 5* & C & DEFINITIONS. $X \bullet A$ REAL VARIABLE \\
\hline 6* & C & $S I(X)=$ INTEGRAL (SIN T/T) DT FROM 0 TO $X$ \\
\hline 7* & C & $S I(-X)=-S I(x)$ \\
\hline $\begin{array}{l}8 * \\
9 *\end{array}$ & $C$ & $\begin{array}{l}C I(X)=\text { GAMMA+LN } X+I N T E G R A L((\operatorname{COS} T-1) / T) D T \text { FROM } 0 \text { TO } X \\
C I(-X)=C I(X)-I \text { PI }\end{array}$ \\
\hline $10 *$ & C & $E I(X)=-P \cdot V \cdot I N T E G R A L(E X P(-T) / T) D T$ FROM $-X$ TO INFINITY \\
\hline 1* & C & $\operatorname{EXNEI}(X)=\operatorname{EXP}(-X) * E I(X)$ \\
\hline 2* & $C$ & INTEGRAL $(E X P(-T) / T)$ DT FROM $\times$ TO INFTNITY, OFTEN \\
\hline $13 *$ & $C$ & DENOTED BY - EI $(-X)=E 1(X)$, (SEE AUTOMATIC COMPUTING \\
\hline $14 *$ & C & METHODS FOR SPECIAL FUNCTIONS, PART II. THE EXPO- \\
\hline 15* & C & NENTIAL INTEGRAL EN $(x)$, J. OF RFSEARCH NRS, 78B, \\
\hline $16 *$ & C & OCTOBER-DECEMBER 1974, PP. 199-216.) \\
\hline 17* & C & SHI $(X)=$ INTEGRAL (SINH T/T)DT FROM 0 TO $X$ \\
\hline $18 *$ & C & $\operatorname{SHI}(-X)=-\operatorname{SHI}(X)$ \\
\hline 19* & C & CHI $(X)=$ GAMMA + LN $X+$ INTEGRAL $((\operatorname{COSH} T-1) / T) \cap T$ FROM 0 TO $X$ \\
\hline $0 *$ & C & $\mathrm{CHI}(-x)=\mathrm{CHI}(x)-I P I$ \\
\hline 21* & C & GAMMA (EULER'S CONSTANT) $=.5772156649 \ldots$ \\
\hline 22* & C & SPECIAL CASES \\
\hline 23* & C & $x=0$ \\
\hline 24* & C & $\operatorname{SI}(0)=S H I(0)=0$ \\
\hline 5* & C & CI $(0)=E I(0)=E X N E I(0)=C H I(0)=-I N F I N I T Y$ \\
\hline $\begin{array}{l}26 * \\
27 *\end{array}$ & $\begin{array}{l}c \\
C\end{array}$ & $\begin{array}{l}\text { =-MAX. MACH. VALUE (RINF) } \\
\text { LIMITING VALUES - } X \text { APPROACHES INFINTTY }\end{array}$ \\
\hline $28 *$ & C & $S I(X)=P I / 2$ \\
\hline 29* & C & $C I(X)=0$ \\
\hline $30 *$ & C & $E I(X)=\operatorname{SHI}(X)=\mathrm{CHI}(X)=\operatorname{INFINITY}(R I N F)$ \\
\hline $31 *$ & C & $\operatorname{EXNEI}(X)=0$ \\
\hline 32* & C & USAGE. CALL SICIEI (IC,X,SI,CI,CII,EI,EXNEI,SHI,CHI,CHII, \\
\hline 33* & C & IERR) \\
\hline $34 *$ & C & FORMAL PARAMETERS \\
\hline $35 *$ & C & INTEGER TYPE \\
\hline $36 *$ & c & FUNCTIONS TO BE COMPIITED \\
\hline $37 *$ & C & SI,CI \\
\hline 38* & C & EI, EXNEI \\
\hline 39* & C & EI, EXNEI, SHI, CHI \\
\hline 40* & C & $\mathrm{SI}, \mathrm{CI}, \mathrm{EI}, \mathrm{EXNEI}, \mathrm{SHI}, \mathrm{CHI}$ \\
\hline 41* & C & REAL OR DOURLE PRECISION TYPE \\
\hline $42 *$ & C & (SAME TYPE AS X) \\
\hline 43* & C & $C I+I \quad C I I=C I(X)$ \\
\hline 44* & C & $E I=E I(X)$ \\
\hline $45 *$ & C & EXNEI $=\operatorname{EXP}(-X) * \operatorname{EI}(X)$ \\
\hline 46* & c & $\operatorname{SHI}=\operatorname{SHI}(X)$ \\
\hline 47* & C & $\mathrm{CHI}+\mathrm{I} \quad \mathrm{CHII}=\mathrm{CHI}(\mathrm{X})$ \\
\hline 48* & C & INTEGER TYPE \\
\hline 49* & C & $X$.GE. 0. NORMAL RETURN \\
\hline $50 *$ & C & $X$. LT. O. ERROR RETURN IF \\
\hline $51 *$ & C & $I C=2$ \\
\hline $52 *$ & C & MODIFICATIONS. \\
\hline $53 *$ & C & THE CODE IS SET UP FOR DOURI_E PRECISION COMPUTATION \\
\hline 54 & C & WITH DOUBLE PRECISION TYPE STATEMENTS \\
\hline $55 *$ & C & DOUBLE PRECISION FUNCTION REFERENCES AND, PARTICU- \\
\hline $56 *$ & C & LARLY,FOR THE UNIVAC 1108 WITH (SEE DEFINITIONS BELOW) \\
\hline $57 *$ & $C$ & RINF APPROX. $2 * * 1023$, UL.SC $=2 * * 56, N B M=60$ AND OTHER \\
\hline 58* & C & CONSTANTS IN DOURLE PRECISION FORMAT TO 19 SIGNIFICANT \\
\hline
\end{tabular}




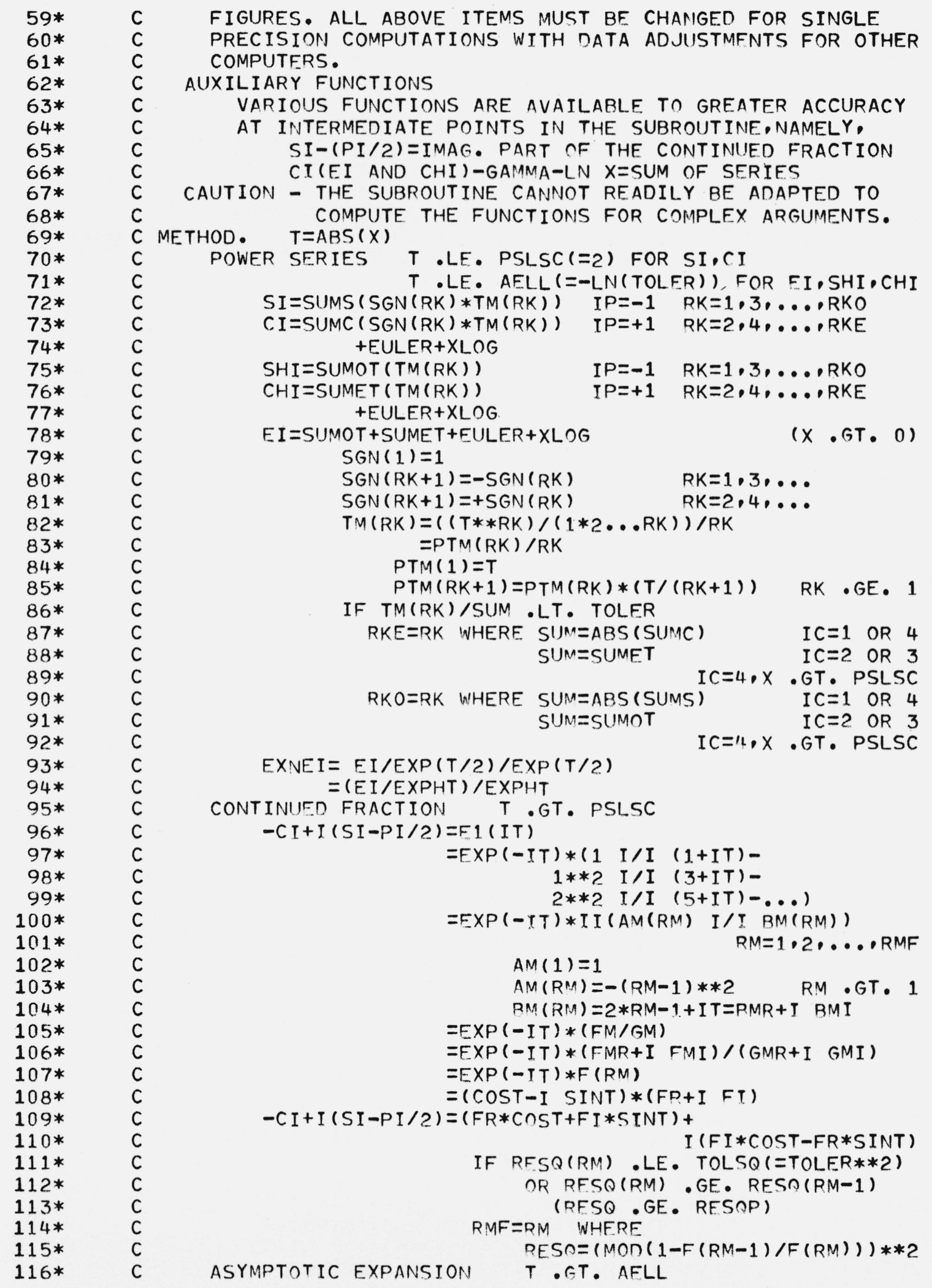




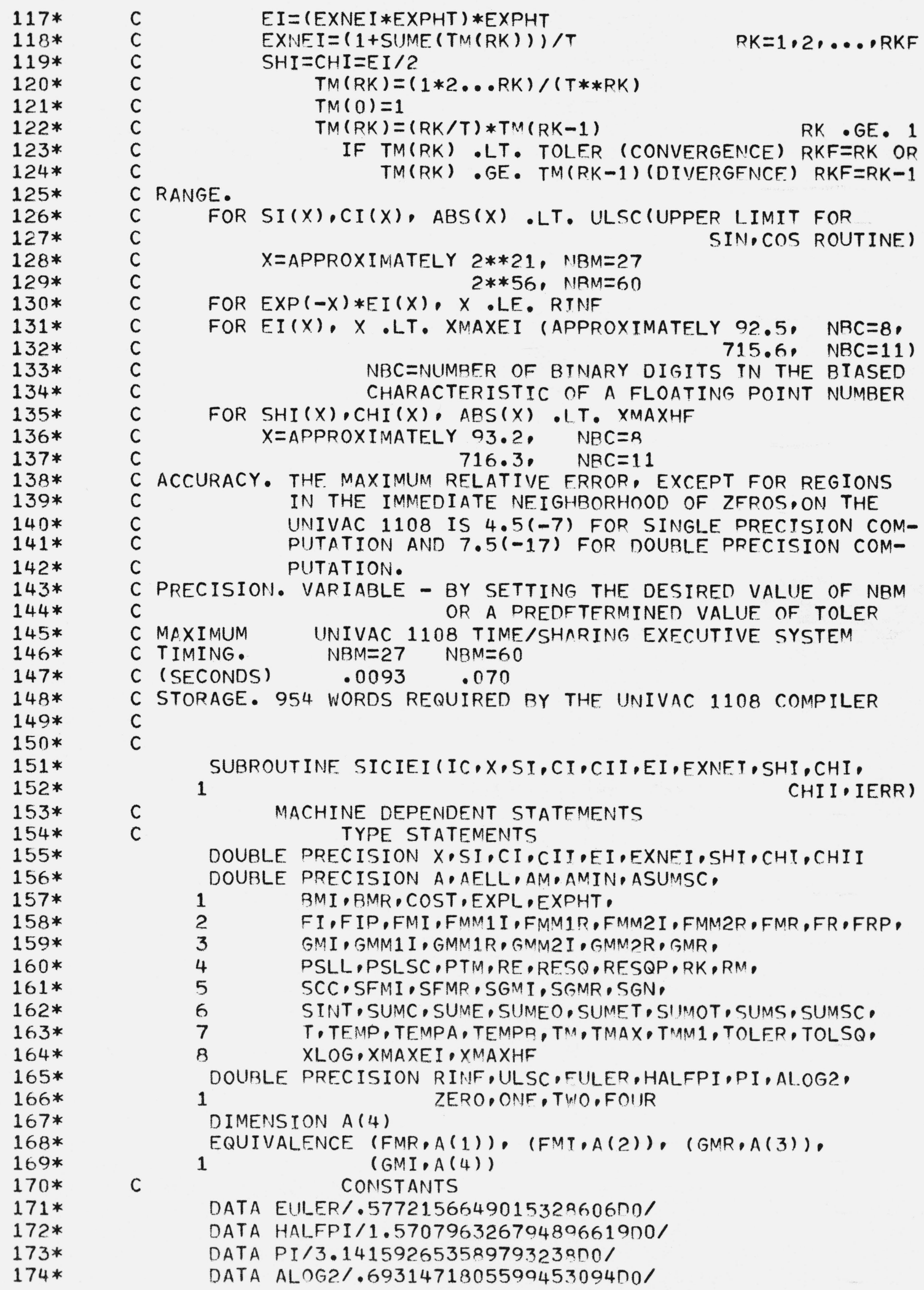




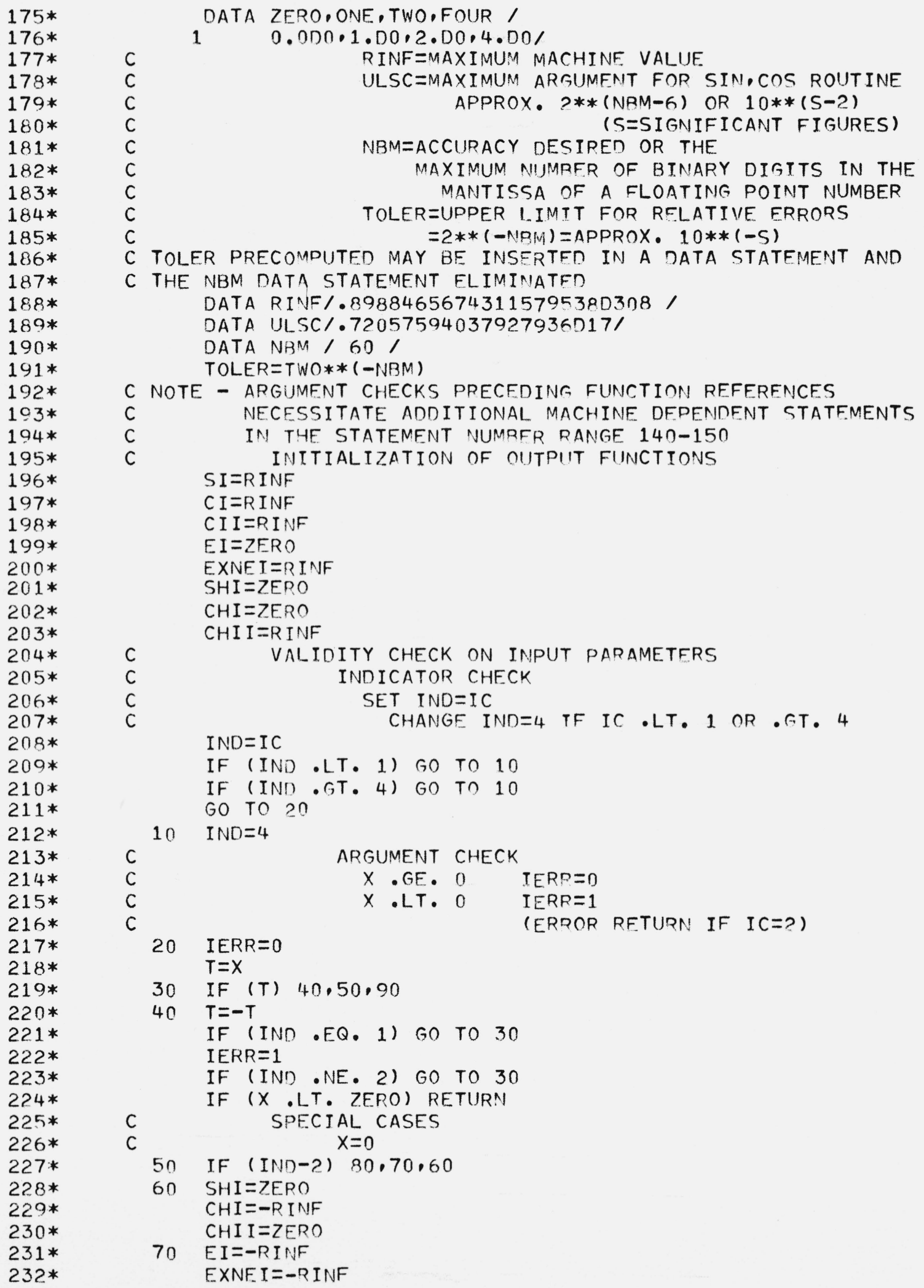




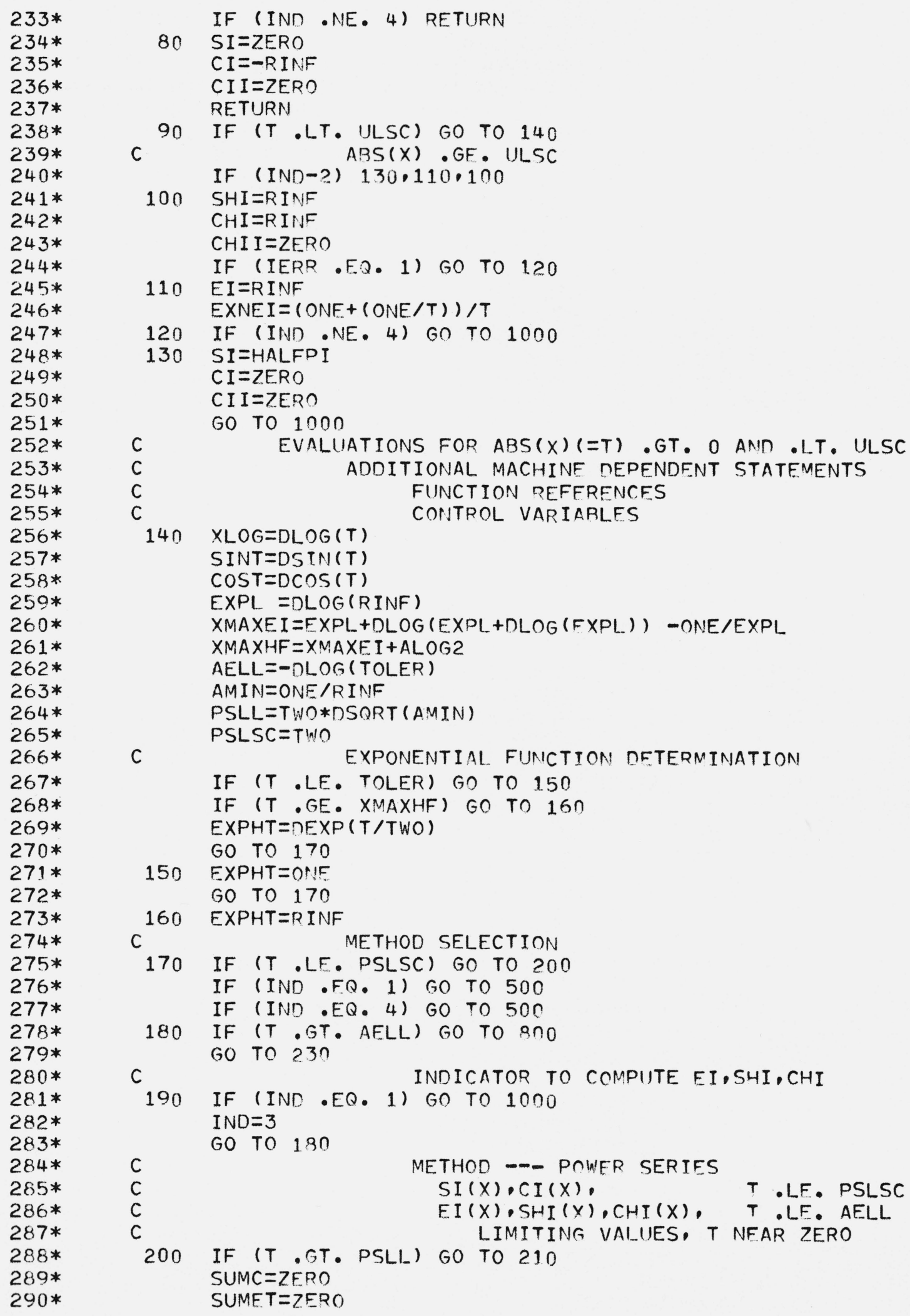




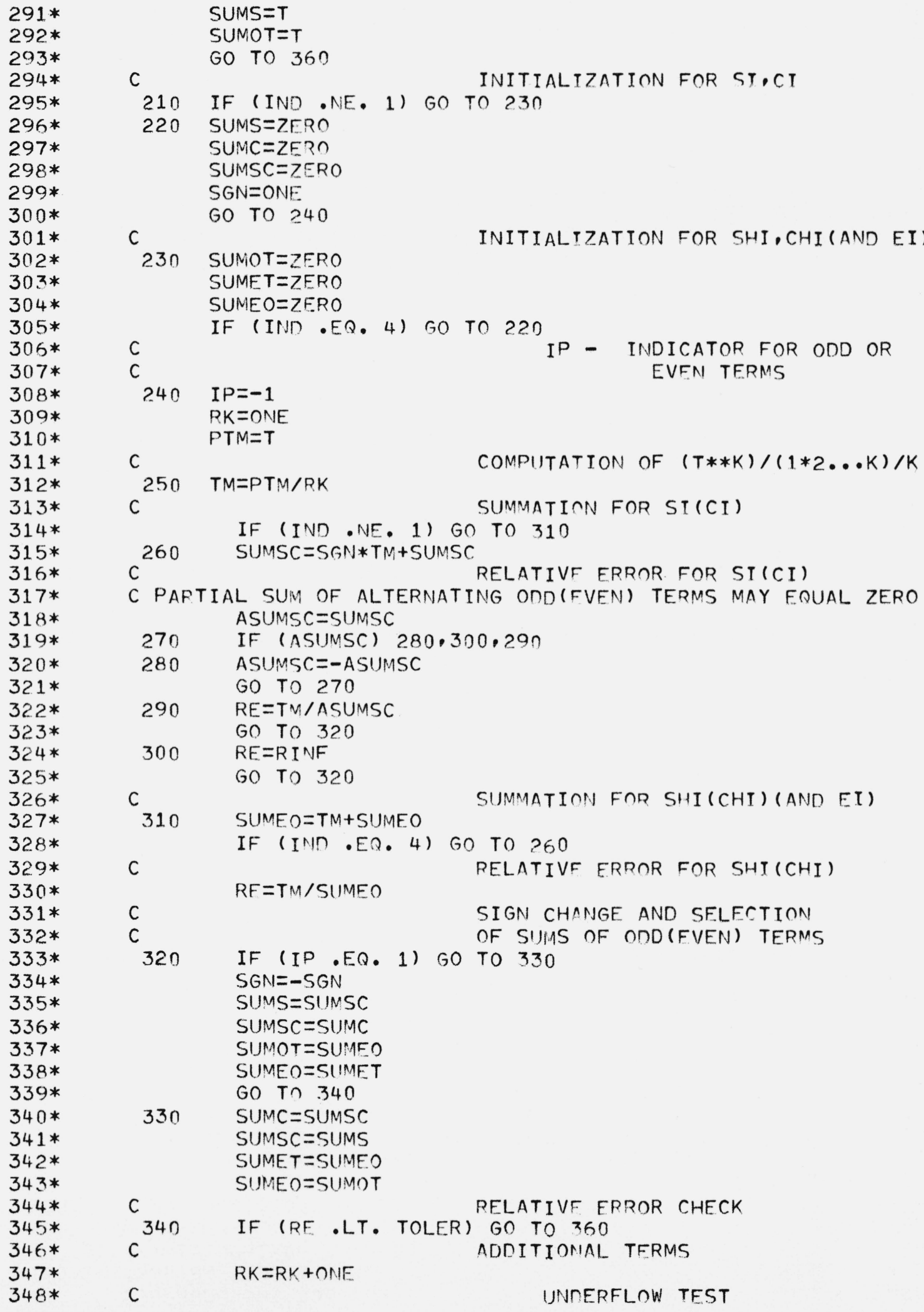




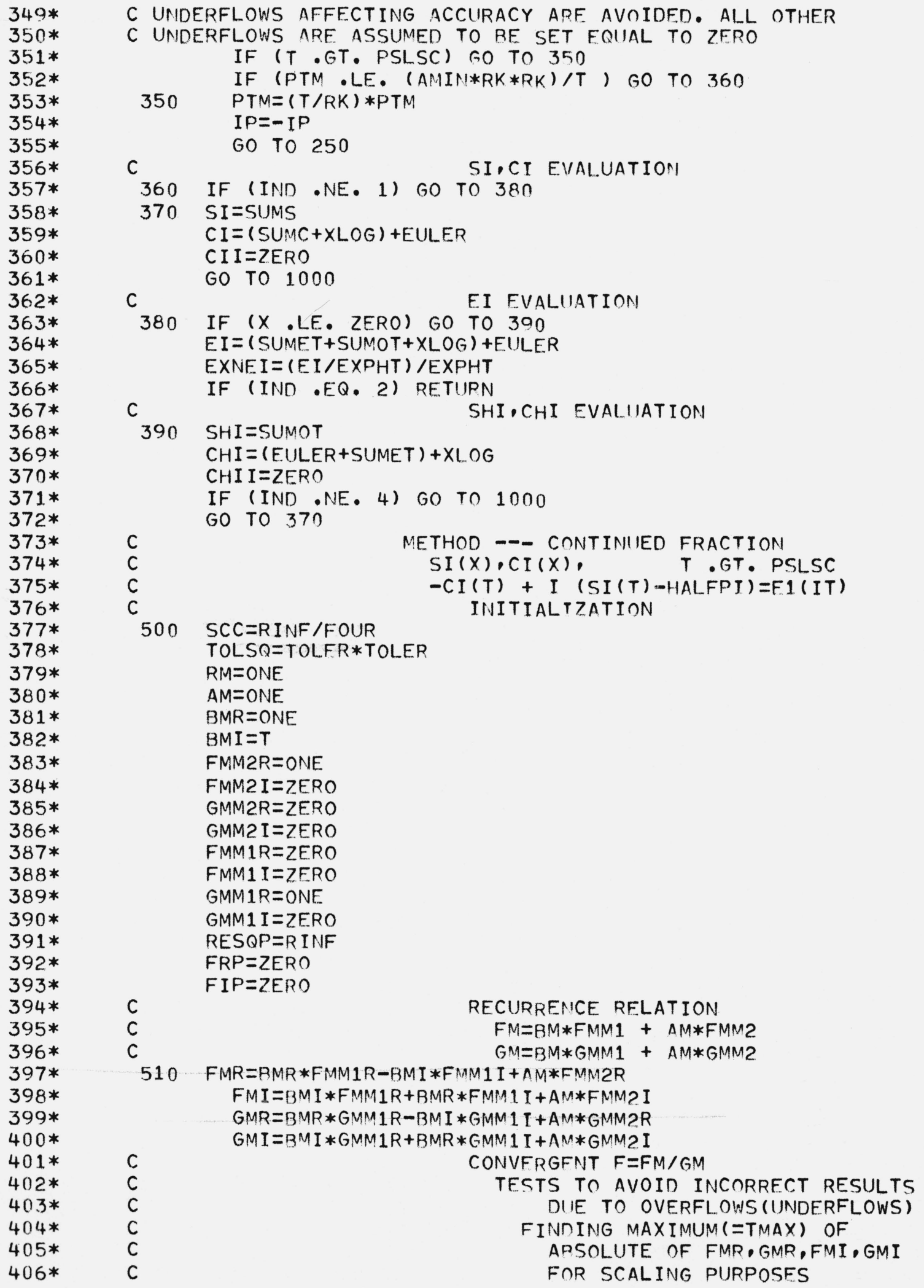




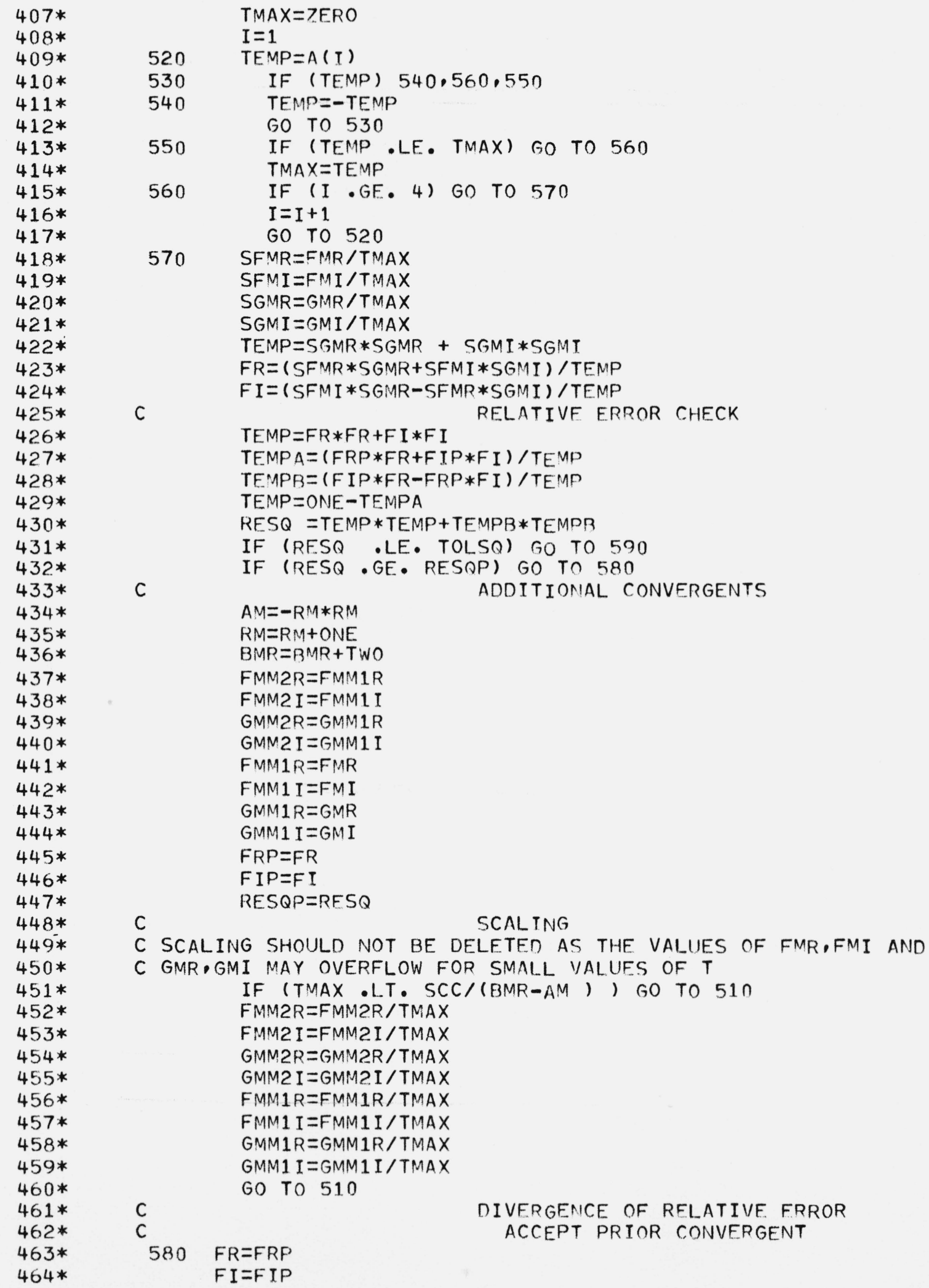




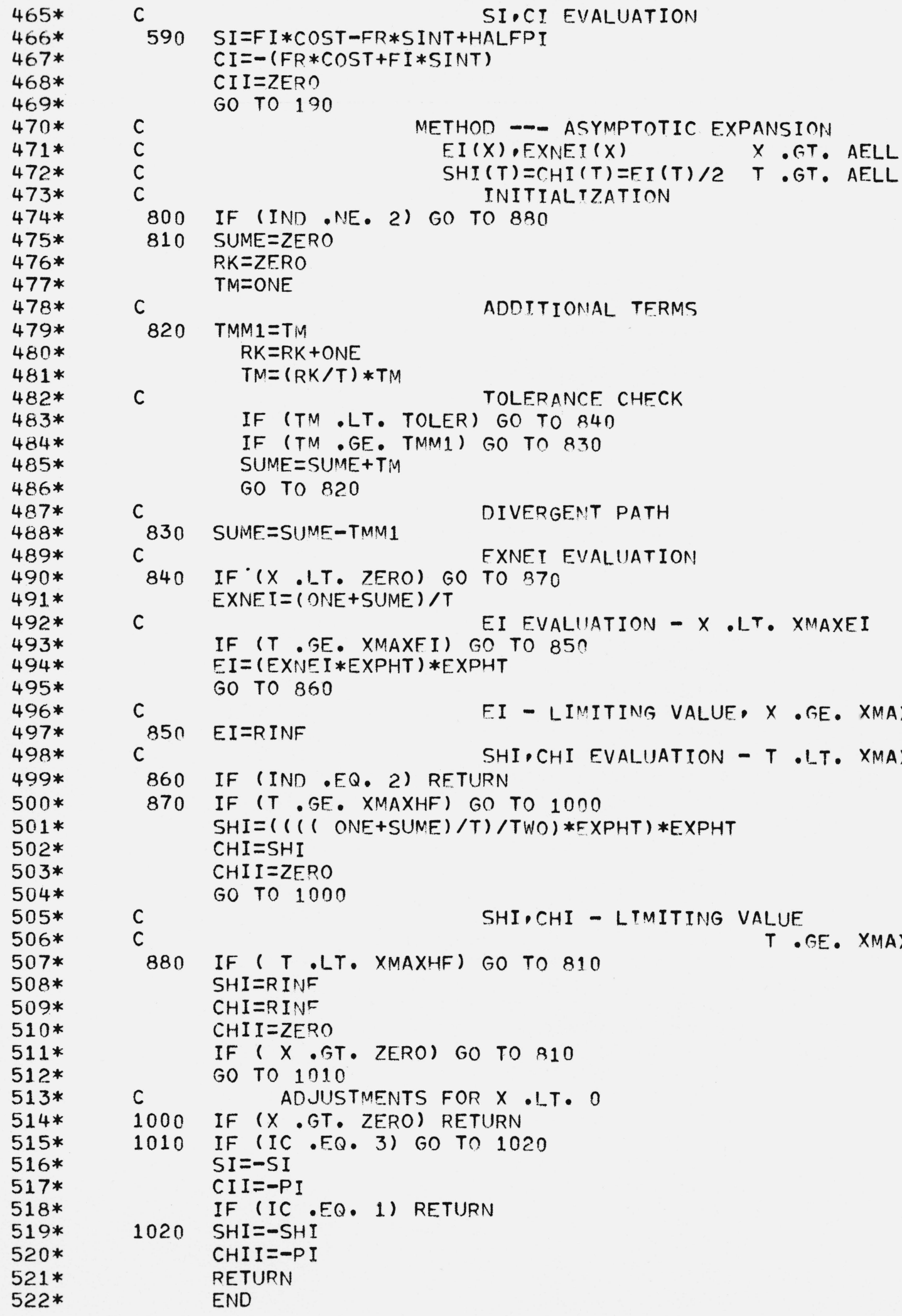


0$$
.1-00
$$$$
.2-001
$$$$
\text { .3-001 }
$$$$
\begin{array}{r}
.4-001 \\
.5-001
\end{array}
$$$$
.6-001
$$$$
\text { .7-001 }
$$$$
\text { .8-001 }
$$$$
\text { .9-001 }
$$$$
1+000
$$$$
2+000
$$$$
3+000
$$$$
4+000
$$$$
.5+000
$$$$
.6+000
$$$$
8+000
$$$$
9+000
$$$$
.1+001
$$$$
.2+001
$$

.9999944444 1999955556 2999850004 3999644461 4999305607 .5998800129 6998094724 7997156101 8995950984

\section{0} 1995560885 2985040438 3964614647 4931074180 .5881288096 6812222391 .7720957854 .8604707107

9460830703 1605412976 1848652527 1758203138 1549931244 1424687551 1454596614 .1574186821
.1665040075

$.7+00$

$8+001$

$.9+001$

$.1+002$

$2+002$
$3+002$

$4+002$

$.4+002$

$.6+002$

$7+002$

$8+002$

$.9+002$

$.1+003$

$.2+003$

$3+003$

$4+003$

$.5+003$

$.6+003$

$.7+003$

$.8+003$

$.9+003$

$.1+004$
9687712181
$-$

$\begin{array}{ll}6470528517 & 85973-002 \\ 8665206276 & 10625-001 \\ 0675616964 & 14691-001 \\ 4469605623 & 17391-001 \\ 5334525894 & 59473-001 \\ 8561513856 & 83629-001 \\ 074459342 & 97997-001 \\ 3834290267 & 56205-001 \\ 3419097919 & 40853-001 \\ 5921185541 & 90930-001 \\ 0456944764 & 16595+000 \\ 6446229574 & 64345+000 \\ 0334263135 & 17445+000 \\ 1626707572 & 76465+000 \\ 9647904006 & 83682+000 \\ 9506811453 & 94252+000 \\ 3889712479 & 89549+000 \\ 4085411696 & 29011+000 \\ & \\ 1353313823 & 17966+000 \\ 7672014819 & 85889+001 \\ 9773025111 & 19732+001 \\ 0555930335 & 85016+001 \\ 7440840073 & 06390+001 \\ 6903102791 & 71420+001 \\ 1476849383 & 61604+001 \\ 8297145120 & 66585+001 \\ 0665342789 & 71085+001 \\ & \\ 3097187938 & 96725+001 \\ 6364334212 & 95137+001 \\ 8373130900 & 67982+001 \\ 7566596201 & 46420+001 \\ 2798559485 & 93775+001 \\ 2644013231 & 99104+001 \\ 2298220467 & 79853+001 \\ 5125172966 & 74798+001 \\ 3805334080 & 46545+001 \\ 5234513880 & 45027+001 \\ 5878557542 & 35465+001 \\ 5231225344 & 08620+001 \\ 0132144796 & 40848+001 \\ 3434162096 & 10243+001 \\ 3169426317 & 07478+001 \\ 3702809228 & 14464+001 \\ 0846382718 & 80577+001 \\ 0335292159 & 62388+001 \\ & \end{array}$

$-.4027979520$

$-.3334907338$

$-.2929567223$

. 2419141543

$-.2419141543$

$-.2237094916$

$-.2052112552$

-.1832754260

$-.1727868386$

-. 1042205595

$-.6491729329$

$-.3788093464$

$-.1777840788$

$-.2227070695$

.1005147070

.1005147070

.2760678304

.3374039229

.4229808287

.1196297860

$-.1409816978$

$-.1900297496$

$-.6805724389$

.7669527848

.1224338825
.5534753133

$-.4545643300$

4441982084

$-.3303241728$

.1902000789

$-.5628386324$

$-.4813243377$

.1092198847
-.1240250115

.9240250115

$-.5148825142$

-. 4378446093

$-.3332199918$

$-.2123988830$

$-.9320008144$

.7641202377

.7788100127

.1118158760

$63344+001$

.8263155110

4796277803

$\pi / 2=1.57079$
9823920722

8599613460

9811175640

3009493497

5519082432

8693029859

9543103133

(2007321930

(3)

6572966389

6727819753

2524433208

0661290133

9279762526

0889783268

5246717701

6777286015

0096813466

7486499569

0800032762

8693041163

5664387861

3247126204

2184518382

3200955729
3133607085

4455372634

5353316539

2071143779

6208766961

1163054401

4432152888

3464977037

6431336804

6104921444

027825679

5921117799

846348934

042902545

3809449584

3975633981

9180513118

0500159240

9068228200
4397561453

8102204879

020167602

931669690

138357349

937022506

(7)

6218391310

9772515290

629169066

6181105135

4661757229

5810271070

6027439020

9135892810

5833582233

0434115538

2646203889

8565153198

6472281176

9144898694

8458900116

1683048406

9157630314

2295958268

6416484497

5328299526

687169925

(264409630

812034202

8589549846

723385245

0458829452

5713422489

435539053

6569771749

7045482583

4793666984

7261962053

1487520193

0132017166

2640905181

9398971297

1773882343

$54440+001$

$74545+001$

$13443+001$

$80028+001$

$9704+001$

$78885+001$

$04089+001$

$18002+001$

$65736+001$

$58895+001$

$48965+000$

$44184+000$

$56908+000$

$62561-001$

28616+000

$84097+000$

$80334+000$

$15077+000$ 
X $.1-001--.4017929465 \quad 4266693867$

$-.2899115723$

.2367884598
-.2175282915

$.6-001--.2175282915$

$.7-001-.201080006$

$-.1866884102$

$1+000$

$2+000$

$3+000$

$.4+000$

$.5+000$

$.6+000$

$8+000$

$.9+000$

$1+001$

$2+001$

$3+001$

$5+001$

$-.1622812813$

$-.8217605879$

$-.3026685392$

1047652186

.4542199048

1064907194

1347396548

1622811713

.1895117816

.4954234356

.1963087447

.4018527535

$.6+001$

$8+001$

$9+001$

$.1+002$

$.2+002$

$3+002$

$.4+002$

$5+002$

$.6+002$

$.8+002$

$.9+002$

$1+00$

$2+003$

$.3+003$

$.4+003$

$.5+003$
$6+003$

$.7+003$

$.8+003$

.8598976214

.1915047433

.1037878290

.2492228976

2561565266

3689732094

6039718263

1058563689

936182213

3646352759

.1371416869

.2715552744

3631235233

6496482508

1308647281

2812821397

6298882891

1450978736

3412238865

.1972045137

$.1+004$

4101539023

9402794440

5728261871

5793745242

5516236358

5516236358

5428875184

3469511928

9692766749

0240031565

6582588446

1932479322

6317357992

6242905405

2123259381

6968674413

3559367554

0018901633

6254165580

0056220022

5803177455

2439204803

3550139595

3483826899

7170895876

2418777591

4056588820

672719706

6112415783

7131690963

9047999696

5072519995

8538798219

1593568523

0886657890

7074277342

8862943374

3879314245

0525608526

2752522682

1412383028
7534341058

9227816770

9618312164

6902308916

6147208749

7790326756

(2)

7135014650

6568299922

3310869899

8136901536

8929763883

0523812662

3137330257

7162359274

4419142440

6652093433

7950513022

0833601921

6457202797

091421793

5834003079

3063148272

5757322679

3844014399

4811208040

4006328910

615414332

2072596687

1345154856

0222595544

1401464231

9671004384

2569189493

4939487839

(2088252210

3560124386

0964504841
$-.3977950399$

$59357+001-.3249071300$

. 2499259848

$-.2252401503$

. 2252401503

.1874857552

$84179+001$

$31175+001$

$-.1723351232$

$-.1468381756$

$-.6728006649$

$97772+000$

$93942+000$

$46026+000$

$80237+000$

$85125+000$

$67593+001$

$35829+00$

$16343+001$

$70353+001$

$67653+001$

$23839+002$

$95867+002$

$90690+002$

$45695+003$

$39339+003$

$36222+004$

$85248+004$

$98072+008$

$84575+012$

$06913+016$

$29987+021$

(5)

$97919+033$

$66918+038$

$08254+042$

$64250+085$

$42473+128$

$11718+172$

$64387+21$

$94621+258$

$93011+302$

$14661+345$

$87339+388$

$20236+432$

4945764013

(1)

2131473100

1746297217

1280843565

1131470204

2565886278

1695420039

1266031055

1123740714

1010206252

.

2506281486

2004016096

.

1112348431

.1001002006

$\operatorname{EXP}(-\mathrm{X}) * \operatorname{EI}(\mathrm{X})$

\begin{tabular}{|c|c|c|}
\hline 2615576971 & 3408360703 & $19476+001$ \\
\hline 3015878880 & 1888549128 & $04425+001$ \\
\hline 5380940257 & 4977395174 & $78007+001$ \\
\hline 2574874044 & 8538470778 & $63194+001$ \\
\hline 9907626374 & 1216434311 & $86807+001$ \\
\hline 3782595071 & 0809271777 & $33217+001$ \\
\hline 3138763197 & 4860337705 & $30829+001$ \\
\hline 0791016360 & 9393503175 & $42803+001$ \\
\hline 1427078812 & 0803355460 & $85013+001$ \\
\hline 5476302940 & 1938294633 & $01893+001$ \\
\hline 8313731896 & 8600992150 & $20087+000$ \\
\hline 1524378927 & 5487443901 & $40039+000$ \\
\hline 7839611020 & 0870681109 & $89467-001$ \\
\hline 5127026213 & 2219977961 & $61145+000$ \\
\hline 2870176143 & 1329955834 & $52537+000$ \\
\hline 5216097535 & 3053374545 & $58451+000$ \\
\hline 6336443347 & 4212274854 & $28025+000$ \\
\hline 6079393891 & 3476848207 & $67092+000$ \\
\hline 3506606876 & 5478681919 & $55160+000$ \\
\hline 9007328104 & 3223808083 & $90335+000$ \\
\hline 4864123502 & 8769696756 & $17092+000$ \\
\hline 6362069617 & 7421675826 & $60745+000$ \\
\hline 9105719558 & 0378348094 & $65324+000$ \\
\hline 8159360315 & 3856832629 & $71120+000$ \\
\hline 6579015129 & 0938352318 & $25166+000$ \\
\hline 7340099664 & 7174203305 & $76383+000$ \\
\hline 2321386813 & 5996461057 & $99933+000$ \\
\hline 7341077803 & 4051681354 & $47701+000$ \\
\hline 9648132254 & 5779817983 & $87276-001$ \\
\hline 2361846131 & 5818701748 & $98032-001$ \\
\hline 5975145205 & 8133890489 & $43081-001$ \\
\hline 5943987333 & 5659940616 & $10444-001$ \\
\hline 4813286610 & 0796814766 & $65768-001$ \\
\hline 5101025543 & 4076487427 & $26111-001$ \\
\hline 4032884299 & 9914561805 & $60367-001$ \\
\hline 1495976244 & 6676886934 & $83357-001$ \\
\hline 7748357112 & 3003599184 & 99944-001 \\
\hline 9333012313 & 0841542901 & $12999-002$ \\
\hline 3037826333 & 1099042135 & $67540-002$ \\
\hline 7484941759 & 1294495095 & $34843-002$ \\
\hline 7757734712 & 6302843056 & $26131-002$ \\
\hline 3112400160 & 6469063742 & $31301-002$ \\
\hline 9351634011 & 0181288435 & $03898-002$ \\
\hline 9721409147 & 4398485683 & $85823-002$ \\
\hline 6823895903 & 3663223603 & $11253-002$ \\
\hline 0241207250 & 8068654920 & $21171-002$ \\
\hline
\end{tabular}


$.1-001$
$.2-001$

$.2-001$

$4-001$

$.5-001$

$.5-001$

$7-001$

8-001

9-001

$.1+000$

$2+000$

$3+000$

$4+000$

$5+000$

$.7+000$

$.8+000$

$.9+000$

$1+001$

$3+001$

$.4+001$

$6+001$

$.7+001$

$+001$

$.1+002$

$2+002$

$3+002$

$4+002$

$.6+002$

$7+002$

$.8+002$

$.9+002$

$.1+003$

$2+003$

$3+003$

$.4+003$

$.5+003$

$6+003$

$.7+003$

$8+003$

$9+003$

$.1+004$
.2000044444

.3000150004

4000355572

5000694496

6001200129

7001905835

.800284499

1000555722

200444978

015040562

.4035726687

.5069967498

.6121303965

.

.9414978265

1057250875

2501567433

4973440475

9817326911

2009321182

4299506111

2201899686

5189391515

1246114490

1280782633

844866047

3019859131

.5292810448

.968091106

1823176379

.3507300002
6857084347

1357776372

1815617616

3248241254

1406410698

. 3149441445

.7254893680

1706119432

4076097503

9860225685
5722222505

9777814059

0500619903

6226866293

(

6079350024

6955665134

6372249715

2505699555

4074638634

0501041398

4249363590

1966719583

6338077262

2889984241

7893448638

1143354092

3757285145

3549756414

8598067977

2330344645

5697226390

8616503145

0023055646

8222188283

1994233444

2028294459

0363709853

8056207891

5658454815

6463826941

7898678183

4523999848

5362599975

4269399109

5796784261

0443328945

9431471687

9431471687

6939657122

2628042631

7241885230

7061915140
1136870933

9860097325

4193925798

5724232696

895071106

051467784

7615329532

0730853837

1095310302

5979378947

3659875988

452784597

(12)

2701645733

7184235489

7337248272

1041838252

4443761778

1213478510

6397896419

1163184608

1922673971

1188221070

4181868552

2003165966

7961570925

307071661

\begin{tabular}{l}
0362577428 \\
\hline
\end{tabular}

1112977723

5700732115

9835502192

1284594746

3746575894

6284771755

0441261054

9833837017

1780062193

4822524206
26380-001

$39861-00$

50634-001

75059-001

39980-00

91766-001

50990-00

72843-001

84646-001

$17784+000$

$22252+000$

$38247+000$

$55253+000$

$4146+000$

$54146+000$

(1)

$60092+000$
$42970+000$

$58780+001$

$75424+001$

$27051+001$

$81526+00$

$82843+002$

$53231+002$

$56496+002$

$69467+003$

$09373+003$

$06923+004$

$98444+008$

$19888+012$

$53457+016$

$49936+020$

$61866+024$

$38584+029$

$98960+033$
$34589+037$

$54127+042$

$32125+085$

$71236+128$

$58592+171$

$82193+215$

$2711+215$

$07331+345$

$43669+388$

$01178+431$

$-x$

-. 4027929520

$-.3334707338$

$-.2929117223$

-.2641260133
-.2417891543

$-.2235294916$

$-.2080819121$

. .1946912552
-.1828704260

$-.1722868386$

$-.1022205566$

$-.6041725954$

$-.2988074501$

$-.5277684495$

.1577508933

.5183999848

6813138871

8378669409

2452666922

4960392094

9813547558

2009206353

.4299470102

2201899309

5189391391

.1246114486

1280782633

844866047

3019859131

.5292818448

9680911069

1823176379

.6857084347

1357776372

1815617616

1406410698

7254893680

1706119432

4076097503

.9860225685

8599317164

807800640

2990530534

544674446

8477029858

8998431835

6793692294

1898070283

1943336705

0431467019

708362984

2316884267

403615913

7397866446

7397866446

(1)

8543390042

8020824089

6469145219

7656097602

8231855580

0105951064

9993521072

884892807

3460771253

3486770482

0424544147 